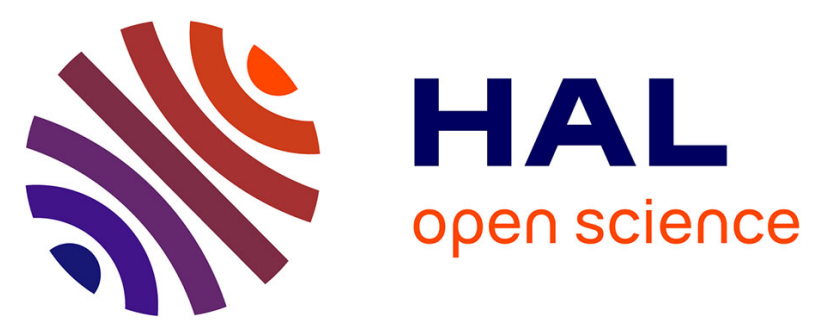

\title{
Observations of carbon monoxide and aerosols from the Terra satellite: Northern Hemisphere variability
}

D P Edwards, L K Emmons, D A Hauglustaine, D A Chu, J C Gille, Y J Kaufman, G Pétron, L N Yurganov, L Giglio, M N Deeter, et al.

\section{- To cite this version:}

D P Edwards, L K Emmons, D A Hauglustaine, D A Chu, J C Gille, et al.. Observations of carbon monoxide and aerosols from the Terra satellite: Northern Hemisphere variability. Journal of Geophysical Research: Atmospheres, 2004, 109 (D24), pp.D24202. 10.1029/2004jd004727 . hal-03222914

\section{HAL Id: hal-03222914 \\ https://hal.science/hal-03222914}

Submitted on 10 May 2021

HAL is a multi-disciplinary open access archive for the deposit and dissemination of scientific research documents, whether they are published or not. The documents may come from teaching and research institutions in France or abroad, or from public or private research centers.
L'archive ouverte pluridisciplinaire HAL, est destinée au dépôt et à la diffusion de documents scientifiques de niveau recherche, publiés ou non, émanant des établissements d'enseignement et de recherche français ou étrangers, des laboratoires publics ou privés. 


\title{
Observations of carbon monoxide and aerosols from the Terra satellite: Northern Hemisphere variability
}

\author{
D. P. Edwards, ${ }^{1}$ L. K. Emmons, ${ }^{1}$ D. A. Hauglustaine, ${ }^{2}$ D. A. Chu, ${ }^{3}$ J. C. Gille, ${ }^{1}$ \\ Y. J. Kaufman, ${ }^{4}$ G. Pétron, ${ }^{1}$ L. N. Yurganov, ${ }^{5}$ L. Giglio, ${ }^{4}$ M. N. Deeter,${ }^{1}$ V. Yudin, ${ }^{1}$ \\ D. C. Ziskin, ${ }^{1}$ J. Warner, ${ }^{1}$ J.-F. Lamarque, ${ }^{1}$ G. L. Francis, ${ }^{1}$ S. P. Ho, ${ }^{1}$ D. Mao, ${ }^{1}$ J. Chen, ${ }^{1}$ \\ E. I. Grechko, ${ }^{6}$ and J. R. Drummond ${ }^{7}$
}

Received 2 March 2004; revised 13 May 2004; accepted 30 June 2004; published 16 December 2004.

[1] Measurements from the Terra satellite launched in December of 1999 provide a global record of the recent interannual variability of tropospheric air quality: carbon monoxide (CO) from the Measurement of Pollution in the Troposphere (MOPITT) instrument and aerosol optical depth (AOD) from the Moderate-Resolution Imaging Spectroradiometer (MODIS). This paper compares and contrasts these data sets with a view to understanding the general features of the overall pollutant loading of the Northern Hemisphere (NH). We present a detailed examination of the seasonal and recent interannual variability of the fine mode AOD and CO column, first considering the variation of the global zonal average for both quantities, and then concentrating on several geographical regions with the aim of isolating different emissions. In a zonal sense, the principal NH sources are related to anthropogenic urban and industrial activity. We show that both the $\mathrm{CO}$ and the AOD zonal seasonal variations reflect the atmospheric oxidant concentration, which determines the primary sink of $\mathrm{CO}$ and the production of sulfate aerosol. As a consequence, the seasonal cycles are several months out of phase, with perturbations resulting from sporadic wildfire or biomass-burning emissions. In these cases, carbonaceous particles dominate the AOD, and this results in the best correlation with the CO column. Of the 4 years of data available from the Terra satellite, the winter and spring of 2002-2003 showed anomalously high $\mathrm{NH}$ pollution compared to the previous years. This was a result of fires in western Russia in the late summer and fall of 2002 and intense fires in the southeast of Russia in the spring and summer of 2003. We examine these events using fire counts from MODIS to indicate the burning regions and investigate how the timing of the fires in relation to atmospheric oxidant concentrations affects the resultant seasonal pollutant loadings. Finally, we trace the emissions from these fires to indicate how intense local pollution sources can impact continental- and global-scale air quality. INDEX TERMS: 0305 Atmospheric Composition and Structure: Aerosols and particles (0345, 4801); 0345 Atmospheric Composition and Structure: Pollution — urban and regional (0305); 0365 Atmospheric Composition and Structure:

Troposphere - composition and chemistry; 0368 Atmospheric Composition and Structure: Troposphereconstituent transport and chemistry; 3360 Meteorology and Atmospheric Dynamics: Remote sensing;

KEYWORDS: Terra, aerosols, carbon monoxide

Citation: Edwards, D. P., et al. (2004), Observations of carbon monoxide and aerosols from the Terra satellite: Northern Hemisphere variability, J. Geophys. Res., 109, D24202, doi:10.1029/2004JD004727.

\footnotetext{
${ }^{1}$ National Center for Atmospheric Research, Boulder, Colorado, USA

${ }^{2}$ Laboratoire des Sciences du Climat et de l'Environnement, Gif-surYvette, France.

${ }^{3}$ Joint Center for Earth Systems Technology, University of Maryland, Baltimore County, Baltimore, Maryland, USA.

${ }^{4}$ NASA Goddard Space Flight Center, Greenbelt, Maryland, USA.

${ }^{5}$ Frontier Research System for Global Change, Yokohama, Japan.

${ }^{6}$ Obukhov Institute of Atmospheric Physics, Moscow, Russia.

${ }^{7}$ Department of Physics, University of Toronto, Toronto, Ontario, Canada.

Copyright 2004 by the American Geophysical Union. 0148-0227/04/2004JD004727
}

\section{Introduction}

[2] Satellite remote sensing offers the best opportunity of making global measurements of tropospheric trace gases and aerosols over extended periods of time. It provides an integrating step between observations of emission sources and subsequent in situ measurements taken some distance away, thus allowing the examination of the impact of intense local pollution sources on continental- and globalscale air quality. Recent developments in aerosol retrieval allow the distinction to be made between coarse and fine mode particles [Kaufman et al., 2002a]. Coarse mode aerosols are usually dust or sea-salt particles. These particles 
are primarily natural, although changing weather patterns and land use practices also play a role in their production. The fine mode particles are formed directly and indirectly from combustion processes, both anthropogenic and wildfire, and these are the same processes that lead to the emission of carbon monoxide (CO) into the atmosphere. $\mathrm{CO}$ is one of the few tropospheric gases that can be successfully monitored from space at the present time. Measurements from the Terra satellite launched in December of 1999 now provide a global record of the recent interannual variability of tropospheric air quality: carbon monoxide (CO) from the Measurement of Pollution in the Troposphere (MOPITT) instrument, and of aerosol optical depth (AOD) from the Moderate-Resolution Imaging Spectroradiometer (MODIS). The goal of this paper is to compare and contrast these data sets with a view to understanding the general features of the overall pollutant loading of the Northern Hemisphere (NH).

[3] Tropospheric aerosols resulting from human activity have a major impact on the ecosystem, through acid deposition and the subsequent effect on agricultural productivity and water quality [Chameides et al., 1999; Adriano and Johnson, 1989]. Poor air quality is also detrimental to human health because of exposure to high concentrations of airborne particulate matter [Beeson et al., 1998]. Possible weather modification due to the effect of increased numbers of condensation nuclei on precipitation processes is still being examined [Rosenfeld, 1999, 2000]. Aerosols also have an important influence on the energy budget [Jacobson, 2001]. Depending on type, they either absorb sunlight and produce a warming, or reflect sunlight back to space producing a cooling of the Earth's surface and changes in cloud microphysics that increase cloud solar reflection. There remains considerable uncertainty as to the magnitude of these effects [Intergovernmental Panel on Climate Change, 2001]. Aerosols also affect the global budgets of atmospheric oxidants by altering photolysis rates, and impact trace gas concentrations by providing sites for heterogeneous chemistry [Bian et al., 2003; Martin et al., 2003; X. Tie et al., Assessment of the global impact of aerosols on tropospheric oxidants, submitted to Journal of Geophysical Research, 2004, hereinafter referred to as Tie et al., submitted manuscript, 2004].

[4] Carbon monoxide is a toxic gas whose principal sources arise from anthropogenic industrial emissions [Olivier et al., 1996], and biomass burning and wildfires [Andreae and Merlet, 2001]. Secondary chemical sources due to the hydrocarbon oxidation are widely distributed and are relatively more important in the remote Southern Hemisphere (SH) [Granier et al., 1999]. CO is a very important trace gas in tropospheric chemistry, and its presence in high concentrations affects the oxidizing capacity of the atmosphere [Logan et al., 1981; Kanakidou and Crutzen, 1999]. An increase in atmospheric CO concentrations could reduce the self-cleansing ability of the atmosphere and thus modify its chemical, physical, and climatological properties. In the presence of nitrogen oxides, it is a precursor to the formation of tropospheric ozone [Ridley et al., 1992], which in turn leads to crop damage and human health problems through its effect on the respiratory system [Tager, 1993].

[5] In section 2 we introduce the measurements of MOPITT CO total column and MODIS fine mode AOD from the Terra satellite. The paper continues in section 3 with a detailed examination of the seasonal and recent interannual variability of these tropospheric contaminants. We consider first the variation of the zonal average for both quantities, and then in section 4 , concentrate on different $\mathrm{NH}$ geographical regions in an attempt to isolate the various emission sources. This is accompanied by a discussion of the sources and sinks of $\mathrm{CO}$ and the aerosol types that contribute to the fine mode AOD. In section 5, we investigate the impact of emissions from boreal fires in Russia in order to explain the high $\mathrm{NH}$ atmospheric pollutant loadings observed during the later part of 2002 and continuing through the spring of 2003. The conclusions of this work are presented in section 6 , with recommendation for how the satellite fine mode AOD and CO data sets may be used together in air quality studies.

\section{Terra Measurements}

[6] Terra/MODIS (http://terra.nasa.gov/About/MODIS/ about modis.html) makes measurements in 36 discrete spectral bands for a number of subsequently retrieved quantities. A 2330-km-wide viewing swath allows MODIS to achieve global coverage in 1-2 days. Atmospheric aerosols have a variety of chemical compositions, with particle sizes ranging from submicron to several microns, and exhibit a range of optical properties. The MODIS AOD retrieval uses 7 channels in the wavelength range from 0.47 to $2.1 \mu \mathrm{m}$ which provide spectral information about aerosol optical properties and underlying surface characteristics. Retrievals over ocean include the aerosol total AOD, effective radius, and AOD fraction due to fine mode particles smaller than $0.5 \mu \mathrm{m}$ [Tanré et al., 1997; Remer et al., 2002]. For air quality studies, the AOD and fine mode fraction over land are of particular interest since these particles are primarily of anthropogenic origin, and retrieval is possible over darker surfaces [Kaufman et al., 1997; Chu et al., 2002]. This requires information on the surface reflectance which is estimated using cloud-free pixels in the $2.1 \mu \mathrm{m}$ visible channel, where fine mode particles are transparent, together with an empirical model relating reflectance at different wavelengths [Kaufman et al., 2002b]. Subsequent derivation of the fine mode AOD, at $10 \times 10 \mathrm{~km}$ nadir horizontal resolution, uses assumptions about the type and size distribution of the aerosols that will be encountered over each geographical region. In this work, we use MODIS AOD and fine mode fraction from Version 4. Validation studies comparing with measurements made by the Aerosol Robotic Network (AERONET) and with Sun photometer measurements are discussed by Chu et al. [2003]. Satisfactory retrieval accuracy is obtained over vegetated and semivegetated regions, with retrieval errors in the range $\Delta \tau=$ $\pm 0.05 \pm 0.20$. Retrievals are not sensitive to aerosol vertical distribution because Rayleigh scattering is much less important at visible wavelengths than it is for other instrument retrievals that use ultraviolet measurements, such as the Total Ozone Mapping Spectrometer (TOMS) [Herman et al., 1997]. As a result, MODIS AOD measurements are often indicative of the higher particulate concentrations in the boundary layer in the vicinity of sources.

[7] Measurements of CO provide a "window" on tropospheric chemistry, and the joint Canadian-U.S. MOPITT 
experiment (http://www.eos.ucar.edu/mopitt/) is providing the first long-term global measurements of $\mathrm{CO}$ in the lower atmosphere. MOPITT is a thermal and near-IR nadir-viewing gas correlation radiometer, and the instrument, measurement, and retrieval techniques are described in detail by Drummond [1992], Edwards et al. [1999], and Deeter et al. [2003], respectively. MOPITT uses a cross-track scan which allows for almost complete coverage of the Earth's surface in about 3 days, with individual pixels of $22 \mathrm{~km} \times 22 \mathrm{~km}$ horizontal resolution. We use the retrieved $\mathrm{CO}$ mixing ratio profiles and total column from data Version 3, which are reported at seven levels through the troposphere. Extensive validation, for a wide variety of locations and environments, has been performed between MOPITT CO retrievals and in situ measurements from aircraft, both as part of a regular sampling program conducted by the NOAA Climate Monitoring and Diagnostics Laboratory (CMDL), and during intensive field campaigns. Results indicate good quantitative agreement between MOPITT and in situ profiles, with the bias mean and standard deviation for the CO column being $4.9 \pm 10.8 \%$ during the first year phase 1 of the mission (discussed in the next section) and $-0.5 \pm 12.1 \%$ in the subsequent years of mission phase 2 [Emmons et al., 2004]. The MOPITT retrieval uses a maximum likelihood approach, and it is important to note that the mixing ratio at a given level reflects the vertical sensitivity of the measurement as defined by the retrieval averaging kernel and a priori profile [Rodgers, 2000; Deeter et al., 2003]. These are also reported as part of the standard product. The measurement technique relies on thermal contrast between the surface and atmosphere, leading to a retrieval dependence on surface temperature, and little sensitivity to $\mathrm{CO}$ in the boundary layer. In general, the MOPITT retrieval can separately resolve $\mathrm{CO}$ in a relatively broad layer of the atmosphere from about $700-500 \mathrm{hPa}$, and in an upper tropospheric layer from about $350-200 \mathrm{hPa}$ [Deeter et al., 2003]. In this respect, it differs from the MODIS AOD retrieval. MOPITT observes CO plumes after they have been vented from the boundary layer, and depending on the prevailing meteorology, this may or may not be close to the emission source. Detailed reports on validation exercises are given by Deeter et al. [2004] and Emmons et al. [2004].

[8] Figure 1 shows the global annual mean distributions of MOPITT CO total column and MODIS fine mode AOD, referenced to $0.55 \mu \mathrm{m}$, for the first full year of Terra operations. The dominant sources of $\mathrm{CO}$ are related to incomplete combustion, and emissions arise from the burning of fossil fuels in urban and industrial areas, the use of biofuels in developing countries, and by biomass burning in the tropics. Northern hemisphere CO loadings are generally higher than those in the SH since the primary sources are associated with human activity and the greater NH population. High CO, due primarily to urban and industrial pollution, is evident over east China, India, eastern United States and Western Europe. Dry season biomass burning in Africa and South America also leads to pronounced $\mathrm{CO}$ plumes. The global average $\mathrm{CO}$ lifetime is about 2 months and varies with season and location [Cicerone, 1988]. This makes CO an excellent tracer for tropospheric transport processes, and plumes from strong emission sources are observed extending great distances. Fine mode aerosols are composed mainly of sulfate and carbonaceous particles, organic carbon (OC) and black carbon (BC). Since these are also produced primarily as a result of anthropogenic combustion processes, there is often good correlation between regions of high fine particulate loading and strong CO sources. Conversely, the distributions of coarse mode AOD (not shown) and CO column do not show similarities, which serves to support the ability of MODIS to distinguish between the two aerosol classes. AOD retrievals are not possible at low solar elevations with zenith angles less than about $72^{\circ}$, or for geographical regions of high surface reflectivity such as deserts and areas covered by snow and ice.

[9] In the remainder of this paper we concentrate on the comparison of retrieved CO total column, units (molecules/ $\mathrm{cm}^{2}$ ), and fine mode AOD, which is dimensionless. These quantities are obviously different physical measures, although both depend on the total number of molecules, or particles, in the vertical column. For comparison of pollutant burdens, the total column mass for both $\mathrm{CO}$ and aerosol, in units of $\left(\mathrm{g} / \mathrm{cm}^{2}\right)$, would be the relevant quantity to consider. This is a straightforward conversion in the case of $\mathrm{CO}$, but is more complicated for aerosol. Aerosol dry mass is related to AOD through the mass extinction efficiency. Calculation of this parameter requires assumptions about aerosol type, size distributions, and hydroscopic properties. The way in which this conversion is performed in a chemical transport model (CTM) is described well by Chin et al. [2002]. In their calculations, the globally averaged mass extinction efficiencies for the principal fine mode particle types, sulfate, $\mathrm{OC}$ and $\mathrm{BC}$, are within a factor of 2 of each other. Even though this difference is not large, it is clear that care must be exercised when inferring the presence of a given aerosol type from the overall AOD distribution. There is also some variation of extinction efficiency with geographical location and changing relative humidity, and assumptions about aerosol type and corresponding optical properties are implicit in the MODIS retrieval process. However, even given these considerations, an analysis of the changing AOD geographical distribution over time should serve as an excellent indication of seasonal and interannual variability of atmospheric aerosol loading, since the global distribution patterns of aerosol mass and AOD are similar [Chin et al., 2002]. In addition, the identification of the aerosol type dominating the MODIS fine mode AOD is one of the goals of the comparison with the MOPITT CO data. This study, based mostly on observational data from satellite instruments, should therefore provide a basis for future work using a CTM to quantify the atmospheric burdens of $\mathrm{CO}$ and the various fine mode aerosol types. We also note that in using total column quantities, the effect of topography is reflected in the geographical distributions of both $\mathrm{CO}$ and AOD. This is evident in Figure 1, especially in mountainous regions and at the ocean/continent boundaries. In the case of the MOPITT CO retrieval where profile quantities are also available, the latter distinction is much less noticeable higher in the troposphere.

\section{Seasonal Variability of Terra $\mathrm{CO}$ and AOD Measurements}

[10] Now that the Terra satellite has been operational for over 4 years, it is possible to present the first multiyear view 

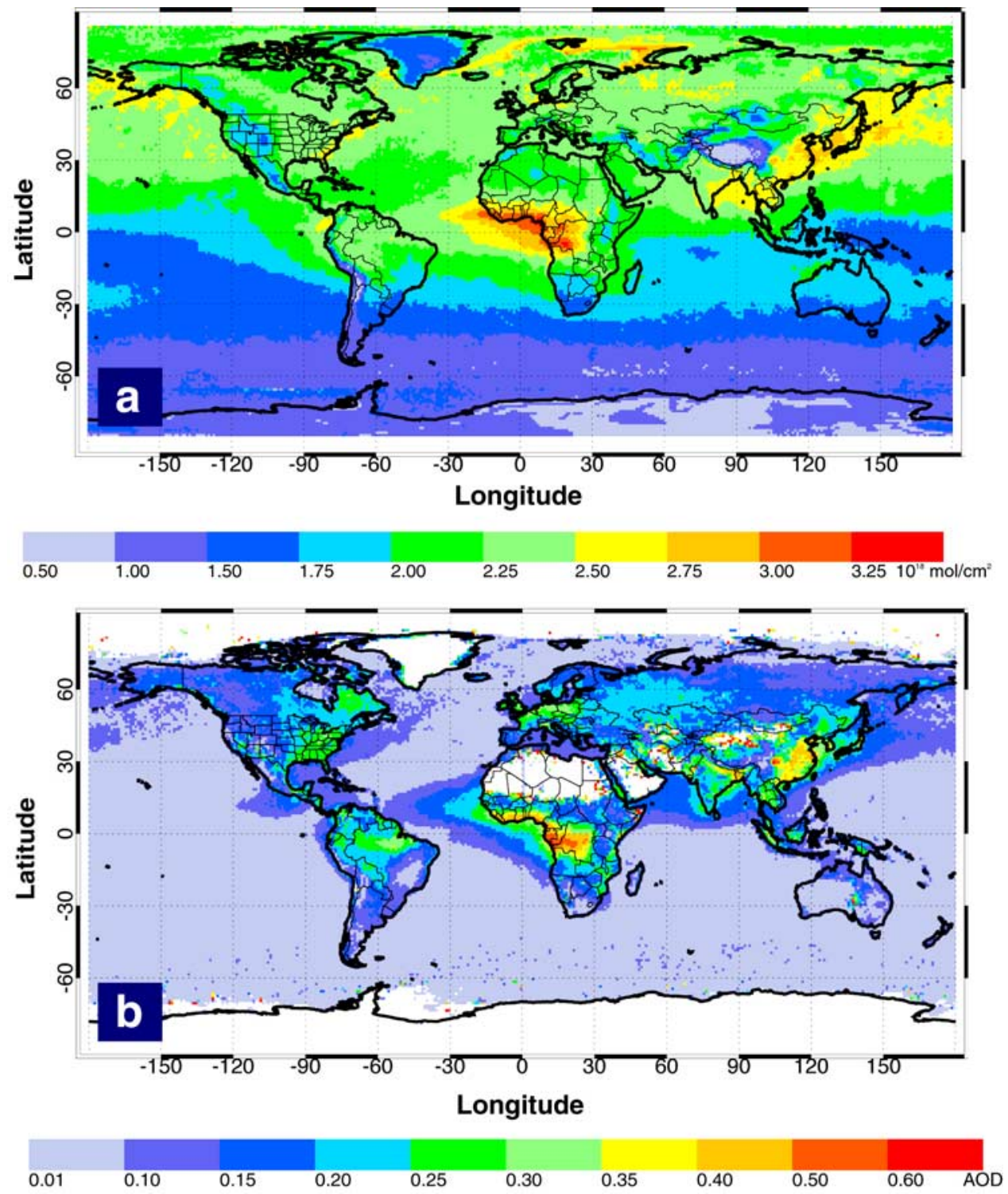

Figure 1. Global annual mean distributions for the first year of Terra operations, April 2000 to March 2001, for (a) Terra/MOPITT CO total column and (b) Terra/MODIS fine mode AOD. Data resolution is $1^{\circ}$ longitude $\times 1^{\circ}$ latitude.

of global air quality from satellite observations. This allows us to examine both the seasonal and interannual variability of CO total column and fine mode AOD, and to compare and contrast the two records. Although Figure 1 shows good correlation between these distributions close to regions of intense emission associated with biomass burning, there are in fact some large differences when the $\mathrm{CO}$ loading and AOD are considered in a zonal sense. Even though CO and fine mode aerosol production generally share the same primary sources related to anthropogenic combustion, explaining the seasonal differences requires a closer examination of sinks and the different aerosol formation mechanisms.

\subsection{Seasonal Variation of Terra/MOPITT CO Column}

[11] The atmospheric loading of $\mathrm{CO}$ shows a pronounced seasonal variation in each hemisphere. Figure 2 shows the recent interannual variation of the zonally averaged $\mathrm{CO}$ total column as measured by MOPITT since March 2000, when the instrument first started taking data, to October 2003. Data for both day and nighttime measurements are included in this average. Intervals where no data are shown correspond to calibration events, or times when the instrument was experiencing problems, such as the period from May to August 2001, during which the instrument experienced a cooler failure and the loss of 4 of the 8 channels. The period prior to this event, referred to as mission phase 1, used information from different channels, and a different retrieval configuration, to the subsequent mission phase 2 . The data comparison for the two periods is described by Emmons et al. [2004]. Validation suggests that the retrieval quality is not significantly different for the two phases of the mission.

[12] It is well known that biomass burning is a major forcing of tropical tropospheric photochemistry [Andreae, 1991]. Emissions depend on biomass type, meteorology and combustion stage, with large amounts of $\mathrm{CO}, \mathrm{CH}_{4}$, and 


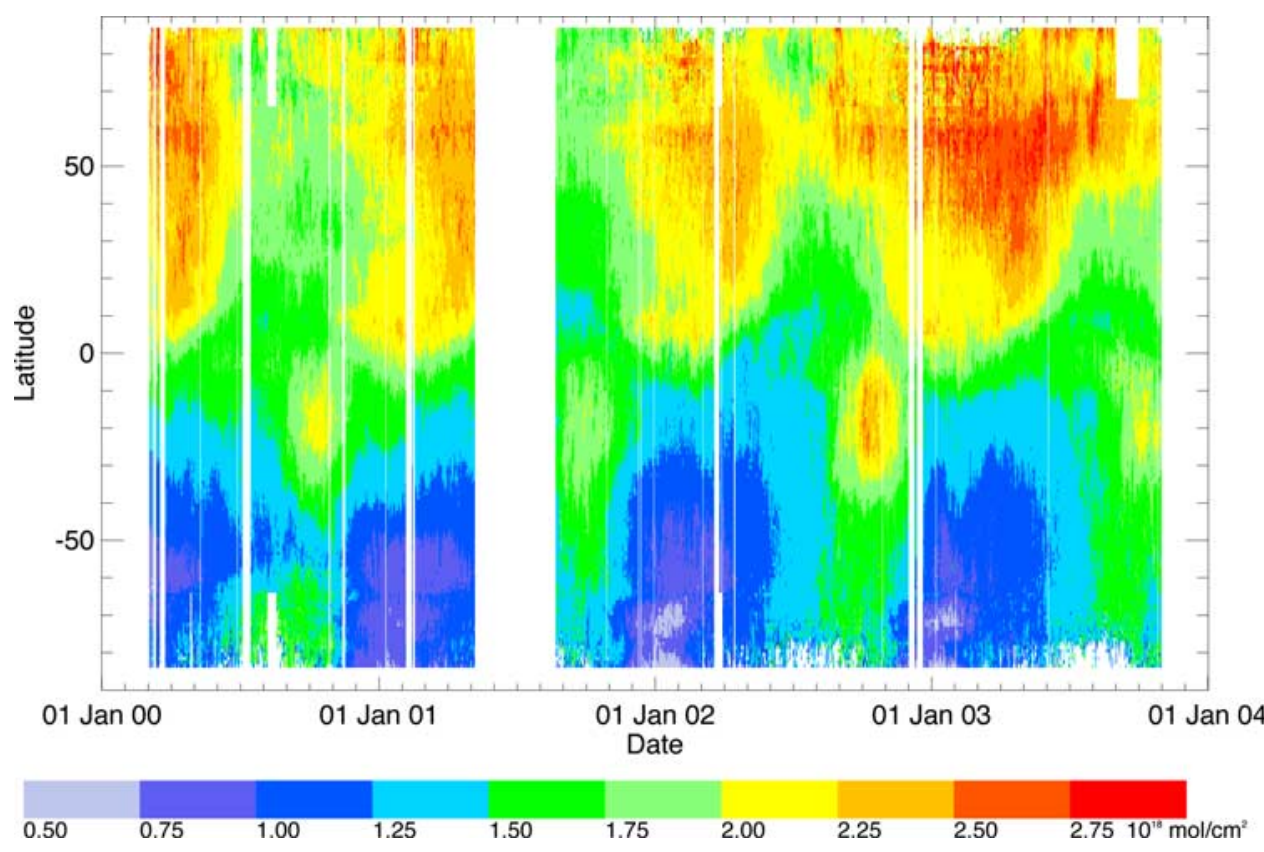

Figure 2. Terra/MOPITT CO zonal mean total column for the period March 2000 to October 2003.

other hydrocarbons being emitted in the later smoldering stages of a fire [Cautenet et al., 1999; Nielsen, 1999]. The recurrent high values of $\mathrm{CO}$ during September and October in the $\mathrm{SH}$ between the Equator and $40^{\circ} \mathrm{S}$ are associated with biomass burning in South America, southern Africa, Indonesia, and northwestern Australia. Of the four burning seasons, 2000-2003, 2001 showed relatively weak emissions while 2002 was particularly strong. Analysis of zonal averages similar to Figure 2, but for particular longitude ranges, shows that for these three years the emissions from southern Africa were the most intense and of similar magnitude each year. Although generally not as intense, the emissions from Indonesia showed the most variation with 2002 showing the strongest emissions, thus leading to the observed zonal interannual variability. In Africa, biomass burning moves northward to the Sahel region and equatorial West Africa with the changing dry season, and this is responsible for the high pollution recorded just north of the equator each year between December and February. The chemistry and transport of emissions from these fires as revealed from an analysis of the available satellite data is discussed in detail by Edwards et al. [2003].

[13] Compared to the $\mathrm{SH}$, the relatively high $\mathrm{CO}$ values in the NH indicate the larger anthropogenic emissions. Industrial/urban emissions from Europe, North America, and Asia peak in the early spring due to fossil fuel burning for heating and increased power requirements, although inversion of the MOPITT CO measurements suggest that the seasonal variation in industrial sources for these regions is not large, about $\pm 15 \%$ of the yearly mean (G. Pétron et al., manuscript in preparation, 2004). The seasonal cycle in zonal CO loading is determined primarily by hydroxyl radical $(\mathrm{OH})$ oxidation, which accounts for about $90 \%$ of the loss, the remainder being mainly due to dry deposition [Thompson, 1992]. The sink is strongest during the summer months under conditions of high solar illumination, since $\mathrm{OH}$ is produced mainly through $\mathrm{O}_{3}$ photolysis and subse- quent reaction with $\mathrm{H}_{2} \mathrm{O}$. This seasonality was previously investigated by Novelli et al. [1998] using ground-based in situ measurements. Also important are the timing and distribution of other sporadic sources such as fires, and the effects of large-scale transport. The zonal impact of a particular emission event will depend on when it occurs in relation to the $\mathrm{OH}$ annual cycle. In terms of zonal $\mathrm{CO}$ burden, the importance of wintertime emissions is usually greater than those during summer, and these may result in high $\mathrm{CO}$ concentrations that persist for several weeks after the emissions themselves have ceased. This is examined further in section 5 with a modeling study to illustrate how, after an intense emission event, the persistence of $\mathrm{CO}$ in the atmosphere depends on the month in which the emission takes place.

\subsection{Seasonal Variation of Terra/MODIS AOD}

[14] The interannual variability in the fine mode AOD is shown in Figure 3 for the period from March 2000 to October 2003. Since the MODIS AOD retrieval is only made during daytime and not for low-Sun conditions, the corresponding seasonal variation in the solar elevation limits the latitudinal data coverage. Data gaps are again due to calibration and instrument events.

[15] The MODIS fine mode AOD peak loading in the NH occurs during the summer, and is out of phase with the maximum $\mathrm{CO}$ by several months. Before discussing the seasonal variability of AOD, we need to consider the specific production mechanisms of the principal fine mode aerosol types along with the seasonal variation of their individual atmospheric loadings. The principal tropospheric aerosols with median radii usually smaller than $0.5 \mu \mathrm{m}$ are sulfate, OC, and BC (Tie et al., submitted manuscript, 2004). In a zonal sense, NH fine mode AOD is usually dominated by sulfate $\left(\mathrm{SO}_{4}^{2-}\right)$ aerosol, and this results primarily from anthropogenic emission of $\mathrm{SO}_{2}$ from fossil fuel use. Other sources of $\mathrm{SO}_{2}$ include volcanic activity, 




Figure 3. Terra/MODIS fine mode zonal mean AOD for the period March 2000 to October 2003.

biomass burning, and oceanic emissions of dimethyl sulfide (DMS), which is a significant sulfate precursor in the SH [Barth et al., 2000]. The global distribution and seasonality of $\mathrm{SO}_{2}$ and sulfate production is described in detail by Rasch et al. [2000]. As with industrial CO emissions, NH emissions of $\mathrm{SO}_{2}$ are somewhat higher during the winter months, although the seasonal variation is only about $\pm 15 \%$ of the yearly mean [Benkovitz et al., 1996]. Modeling studies suggest that the seasonal cycle of sulfate species are controlled by a complex interplay between transport, chemistry, and deposition processes [Rasch et al., 2000]. The $\mathrm{SO}_{2}$ burden shows a significant winter maximum, while the maximum in sulfate occurs in the summer, about half a year out of phase. $\mathrm{SO}_{2}$ oxidation by $\mathrm{OH}$ in the gas phase and by $\mathrm{H}_{2} \mathrm{O}_{2}$ in the aqueous phase are the primary sulfate sources, and in the lower troposphere, both processes are more efficient during summer, because of more clouds in the liquid phase and higher oxidant levels. Wet deposition is the primary sulfate sink, and although this has a strong seasonal variation in the boundary layer, there is little variation in the lower troposphere above. This leads on balance to higher sulfate burdens during summer in this part of the atmosphere. The atmospheric lifetime of anthropogenic sulfate aerosol varies from $2-5$ days depending on geographical region [Rasch et al., 2000].

[16] The most important sources of carbonaceous aerosol, $\mathrm{OC}$ and $\mathrm{BC}$, are direct emissions related to biomass and fossil fuel burning [Liousse et al., 1996]. Smoke from vegetation fires is dominated by fine OC, with varying amounts of $\mathrm{BC}$, which is emitted primarily in the hot flaming stage of the fire. In forest fires, the flaming stage is followed by a longer, cooler, smoldering stage, in which $\mathrm{OC}$, rather then $\mathrm{BC}$, is emitted together with large amounts of CO [Ward et al., 1996; Ferek et al., 1998]. The ratio of emissions between biomass and fossil fuel burning are 1.6 and 0.8 for $\mathrm{OC}$ and $\mathrm{BC}$, respectively, suggesting that biomass burning plays the most important role in control- ling the OC budget [Liousse et al., 1996]. Carbonaceous aerosols are composed of hydrophobic and hydrophilic particles. Within a few days, hydrophobic carbonaceous aerosols undergo aging processes to become hydrophilic. The main sinks of carbonaceous aerosols are dry deposition (for both hydrophobic and hydrophilic particles) and wet deposition (for hydrophilic particles). Lifetime is about 5 days for OC and 6 days for BC [Chin et al., 2002].

[17] In the SH, Figure 3 shows high AOD values which correlate well in terms of geographical position and timing with the corresponding high $\mathrm{CO}$ columns in Figure 2 that can be attributed to biomass burning. In this case we expect the AOD to be determined by carbonaceous aerosol, which is directly emitted, mainly in the form of OC, from the fires. The SH biomass-burning features are the subject of a separate paper, and will not be discussed further here. The $\mathrm{NH}$ wintertime African biomass burning between the equator and $10^{\circ} \mathrm{N}$ is also very evident and makes a significant impact on the global zonal mean, in addition to correlating well with the high $\mathrm{CO}$ emissions from these fires. Compared to the average CO lifetime of several weeks in this region, the much shorter OC lifetime of a few days, and the greater sensitivity of MODIS measurement to the boundary layer, means that the high AOD retrievals are a more reliable indication of biomass-burning source regions than the $\mathrm{CO}$, where the signature tends to 'smear out' in the time it takes for $\mathrm{CO}$ to be transported to the free troposphere.

[18] There is a pronounced increase in AOD northward of $30^{\circ} \mathrm{N}$. This latitude coincides with the southern boundary of the NH industrial regions: the southern borders of the United States and Europe, and with industrial regions of eastern China near Shanghai. There is also a very pronounced maximum to the AOD through the spring and summer months, April-August, an increase by a factor of about 4 over the wintertime values. This is most likely due to increased $\mathrm{NH}$ sulfate aerosol production from industrially emitted $\mathrm{SO}_{2}$. However, the summer months are also a time 


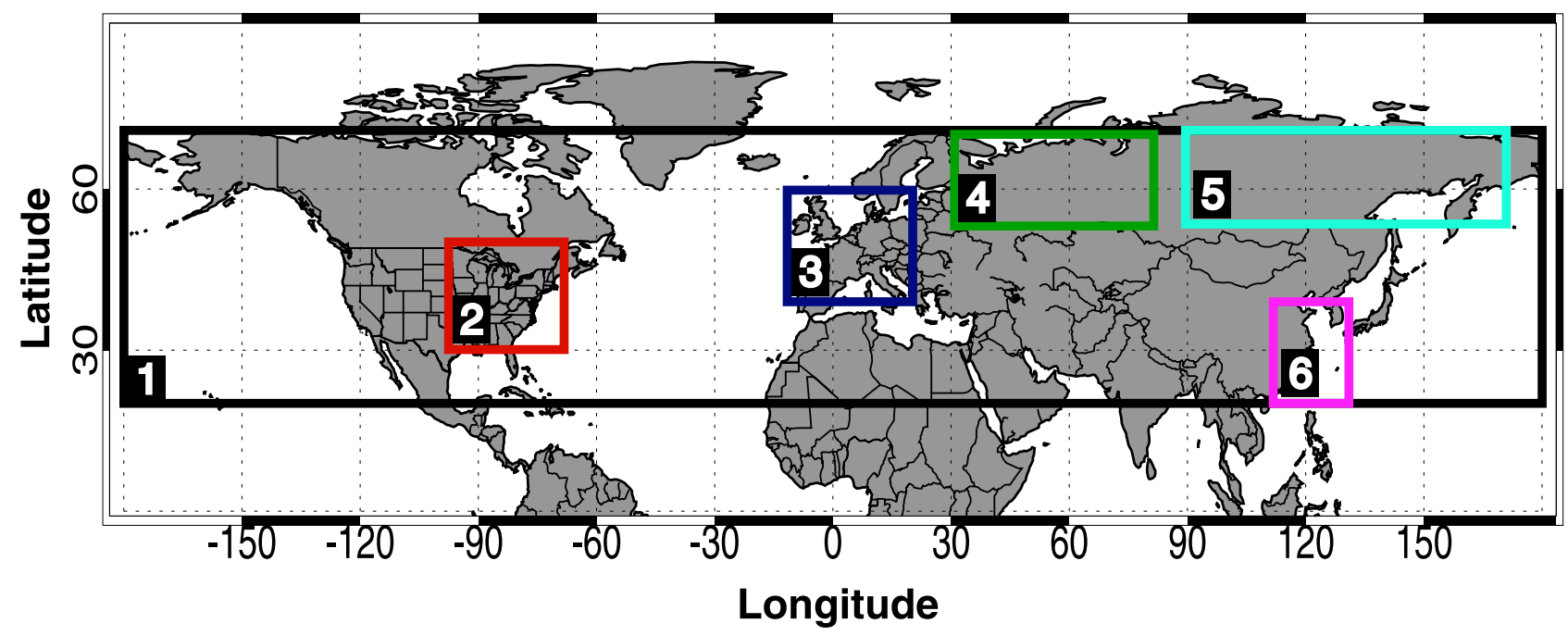

Figure 4. Borders of six regions over which Terra/MOPITT average CO total column and Terra/MODIS fine mode AOD time series are calculated.

of wildfires throughout North America, Europe, and Asia, and, in addition to sulfate, we also expect carbonaceous aerosol to contribute to the AOD. Indeed, the isolated high AOD values that occur during the summer months are probably associated with fire events. This is investigated further in the next section.

\section{Interannual Variability of Air Quality by Region}

[19] It is clear from Figure 2 that the CO loading during the winter-spring of 2002-2003 was considerably greater than that of the previous two winter seasons. In addition to this, the NH CO started increasing much sooner after the previous summer minimum, during August 2002, in comparison to November 2001 in the previous year. Before investigating potential causes for this, it is important to first rule out instrument effects or changes in conditions that might affect the retrieval, especially given the history of MOPITT instrument problems. However, relative to the previous year, the same spring, 2003, increase is seen in the MODIS fine mode AOD, Figure 3, so lending support to this being an indication of significant interannual variability.

[20] In this section we consider the recent interannual variability of $\mathrm{CO}$ column and fine mode AOD within the 6 geographic regions shown in Figure 4. Region 1 covers all longitudes, $180^{\circ} \mathrm{W}$ to $180^{\circ} \mathrm{E}$, and latitudes $20^{\circ}-70^{\circ} \mathrm{N}$. The other regions have been chosen to be representative of different emission regimes, and include the following: 2 , the eastern United States $\left(30^{\circ}-50^{\circ} \mathrm{N}, 100^{\circ}-70^{\circ} \mathrm{W}\right)$; 3 , western Europe $\left(40^{\circ}-60^{\circ} \mathrm{N}, 10^{\circ}-20^{\circ} \mathrm{E}\right)$; 4, western Russia $\left(50^{\circ}-70^{\circ} \mathrm{N}, 30^{\circ}-80^{\circ} \mathrm{E}\right) ; 5$, Siberia $\left(50^{\circ}-70^{\circ} \mathrm{N}\right.$, $\left.90^{\circ}-170^{\circ} \mathrm{E}\right)$; and 6 , eastern China $\left(20^{\circ}-70^{\circ} \mathrm{N}, 110^{\circ}-\right.$ $\left.130^{\circ} \mathrm{E}\right)$. The variation of the MOPITT $\mathrm{CO}$ total column and MODIS fine mode AOD averaged over each of these regions is shown in Figure 5. These data have been smoothed with a running 3 day average to reduce the synoptic noise and improve readability. The traces of region 1, N. Hemisphere, reproduce for $\mathrm{CO}$ column and AOD the average behavior of Figures 2 and 3 within the $20^{\circ}-70^{\circ} \mathrm{N}$ latitude band. Clear seasonal cycles are evident. The maximum $\mathrm{CO}$ loading occurs in April and reaches a minimum in September, with a springtime decline that is faster than the buildup during the fall and winter. The AOD, which on this scale is determined primarily by the sulfate aerosol loading, shows a broad maximum from April to August, with a minimum in December. As noted in the previous section, the primary $\mathrm{NH}$ seasonal cycles of both CO column and AOD are determined by the fairly constant anthropogenic emissions of $\mathrm{CO}$ and $\mathrm{SO}_{2}$ from urban regions and industry, in conjunction with the seasonality of atmospheric oxidant loading.

[21] Although the other regions show the same underlying, oxidant-driven, seasonal variation in $\mathrm{CO}$ column and AOD as the zonal means of region 1, they do so to differing degrees. In general, eastern United States and western Europe, regions 2 and 3, show a clear seasonality. The summer-to-winter ratio for AOD is about 3, slightly higher than the factor of 2 suggested by the modeling study of Rasch et al. [2000]. The ratio for CO column appears to be less than 2 . The seasonality is progressively less pronounced for western Russia, Siberia, and eastern China, regions 4-6, and occurs in both the CO column and AOD traces. We start with an examination of western Russia, region 4. During 2000 and 2001, the CO column follows a variation similar to that of western Europe, region 3. Then in July, August and September 2002 there is a marked increase in the $\mathrm{CO}$ loading over this region, in exactly those months that marked the minimum in 2000. In the next section, we show that this was due to wildfires whose emissions were sufficiently high to prevent the zonal CO loading from reaching its usual minimum in September, and resulted in an early buildup of $\mathrm{NH} \mathrm{CO}$ during the winter of 2002-2003. In addition to high CO emissions, these fires also emit large amounts of carbonaceous aerosol into the atmosphere, and a corresponding peak is seen at this time in the AOD.

[22] In general, we find that the main perturbations from the usual seasonal cycles of $\mathrm{CO}$ column and AOD are consistent with sporadic fire emissions. The location and 



Figure 5. Time series of the Terra/MOPITT average CO total column, left axis in red, and Terra/MODIS fine mode AOD, right axis in blue, for the geographical regions defined in Figure 4. Note changes in scale.

timing of burning is identified in this work using fire counts from Terra/MODIS, and is described in the next section. In region 2, the eastern United States, increased CO loading is observed in August 2000. This resulted from pollution transported from wildfires in the western states of Montana and Idaho [Lamarque et al., 2003]. The CO peak in July
2002 was again due to transport of wildfire emissions into the eastern United States, this time from burning in Ontario, Canada. Unfortunately, MODIS AOD data are not available for some of these times. The relatively long $\mathrm{CO}$ lifetime also means that intense fire emissions can significantly affect the air quality on a global scale. The particularly high $\mathrm{CO}$ 
columns seen over the eastern United States in the spring of 2003 were due to long-range transport of fire emissions from southeastern Russia. This is discussed in the next section. However, we note here that high $\mathrm{CO}$ columns were observed over Siberia, region 5, because of this widespread burning in the region throughout the spring and summer months. Emissions were sufficient to delay the onset of the summer $\mathrm{CO}$ minimum and to produce very high zonal springtime $\mathrm{CO}$ loadings, as indicated by the $\mathrm{NH}$ trace, region 1. A similar seasonal variation is obtained from CO surface in situ measurements. The flask sample data obtained by the NOAA CMDL from the station in Ulaan Uul, Mongolia, which can be easily displayed on the CMDL website (http://www.cmdl.noaa.gov/ccgg/), show an almost identical pattern to the MOPITT CO column trace for Siberia, region 5. Because the lifetime of carbonaceous aerosol is only a few days, we do not see a corresponding springtime, 2003, increase in the AOD over the eastern United States, region 2, above that observed during the previous year which can be attributed to the local seasonal production of sulfate aerosol. However, in Siberia, region 5, where the fires are burning, there is a marked increase in the AOD at this time. The signature of these springtime fires is followed by a second peak in the AOD due to Siberian fires during July and August 2003. This later burning also has a local impact on the $\mathrm{CO}$ column, but because the $\mathrm{OH}$ loading is higher at this time of year compared to the springtime, the $\mathrm{CO}$ does not persist long enough to have such a marked effect on the zonal loading. Further signatures of regional fire emissions can be seen in the traces for the eastern United States and western Europe, regions 2 and 3, respectively, during August 2003. These are more evident in the AOD than in the $\mathrm{CO}$ column because of the high oxidant concentration at this time.

[23] Emissions from eastern China, region 6, are particularly intense because of the rapidly growing industrialization and heavy reliance on coal and biofuel burning compared to the developed western countries. Compared with the others, this region exhibits a relatively small seasonal variation, in agreement with modeling studies [Rasch et al., 2000]. A significant fraction of the AOD in this region might be due to direct industrial emissions of OC (Tie et al., submitted manuscript, 2004).

\section{Impact on Air Quality of Russian Fires}

[24] The CO column and fine mode AOD records of the recent interannual variability shown in Figures 2, 3, and 5 point to significantly enhanced levels of $\mathrm{NH}$ pollution from fall 2002 through the summer of 2003. The analysis of the previous section suggests that fire emissions from western Russia and Siberia were responsible.

[25] To investigate further the onset of the poor air quality period during winter-spring 2002-2003, we look in more detail at the CO and AOD records of September 2002. As noted in the previous section, it is at the end of August and beginning of September that the $\mathrm{NH} \mathrm{CO}$, as shown in the MOPITT zonal mean of Figure 2, first shows significant accumulation, at a time that marked the minimum loading in the previous year. Examination of Figure 3 also indicates high "spikes" of fine mode AOD around this time. In September 2002 both fine mode AOD and CO column were almost double the values of the same month of 2000. Figure 6 shows the 1-15 September 2002 mean distributions of MOPITT CO total column and MODIS fine mode AOD, and the August 2002 MODIS fire counts over northern Europe and western Russia. All these products come from the Terra satellite. The identification of wildfires and biomass-burning source regions over such large, and often remote, geographical regions is made possible by satellite observations. Fire pixels are identified according to absolute and relative difference criteria between various MODIS channels [Giglio et al., 2003]. The $0.5^{\circ} \times$ $0.5^{\circ}$ monthly gridded fire counts are corrected for spatial variability in the frequency of satellite overpasses and missing observations. To perform such a correction, and to reduce the effect of day-to-day variation in fire counts due to cloud obscuration, it is most reliable to generate composite fire count maps for periods of several weeks. Although satellite observations are capable of detecting the presence of a fire, care must be exercised when using fire counts alone to define emissions. Count information alone does not contain information about the fire intensity, biomass burned, or the specific emissions.

[26] For northern latitudes at this time, the region shown in Figure 6 had the highest combination of fire counts, CO column, and fine mode AOD, and was the cause of the high values recorded in the zonal mean. The pollutant concentration reached a maximum in early September. This resulted from fires that had been burning through August, and a better correlation was found with the August fire count distribution than with that of September. The number of fires decreased sharply during September and October and were effectively finished by November. In the figure, the correlation between $\mathrm{CO}$ and AOD, and fire counts, is generally very good, and it is clear that burning in eastern Europe and western Russia, rather than industrial or urban sources, were responsible for the pollutant emissions. High values of AOD are a better indication of fire locations than the CO column because of the high sensitivity of the MODIS measurement to the boundary layer. The development of a distinct plume from the emissions is also evident in both the MOPITT and MODIS measurements, and high pollution levels can be seen north of the Russia-Kazakhstan border around $60^{\circ} \mathrm{N}, 70^{\circ} \mathrm{E}$.

[27] The smoke pollution in the region around Moscow between July and September 2002 caused a dramatic reduction in visibility, to less than $100 \mathrm{~m}$ in the capital, and also had detrimental impacts on the health of the Moscovite population [International Forest Fire News $(I F F N), 2003]$. The fires reached a peak on 6 September with a large increase in the number of peat and forest fires. The high pollution levels are shown in the retrievals of total $\mathrm{CO}$ column, Figure 7, from ground-based infrared grating spectrometer measurements [Dianov-Klokov et al., 1989], both in Moscow itself and at the research station at Zvenigorod, at a distance of $60 \mathrm{~km}$ West of the capital. These measurements are discussed in detail by Fokeeva et al. [2004]. The figure shows high CO levels in Moscow during the spring which are not reflected in the Zvenigorod data, suggesting that they were due to urban pollution from within the city. High $\mathrm{CO}$ values were captured at both sites at the end of August and beginning of September. The mean CO column values at Zvenigorod for the years 1993-1997 

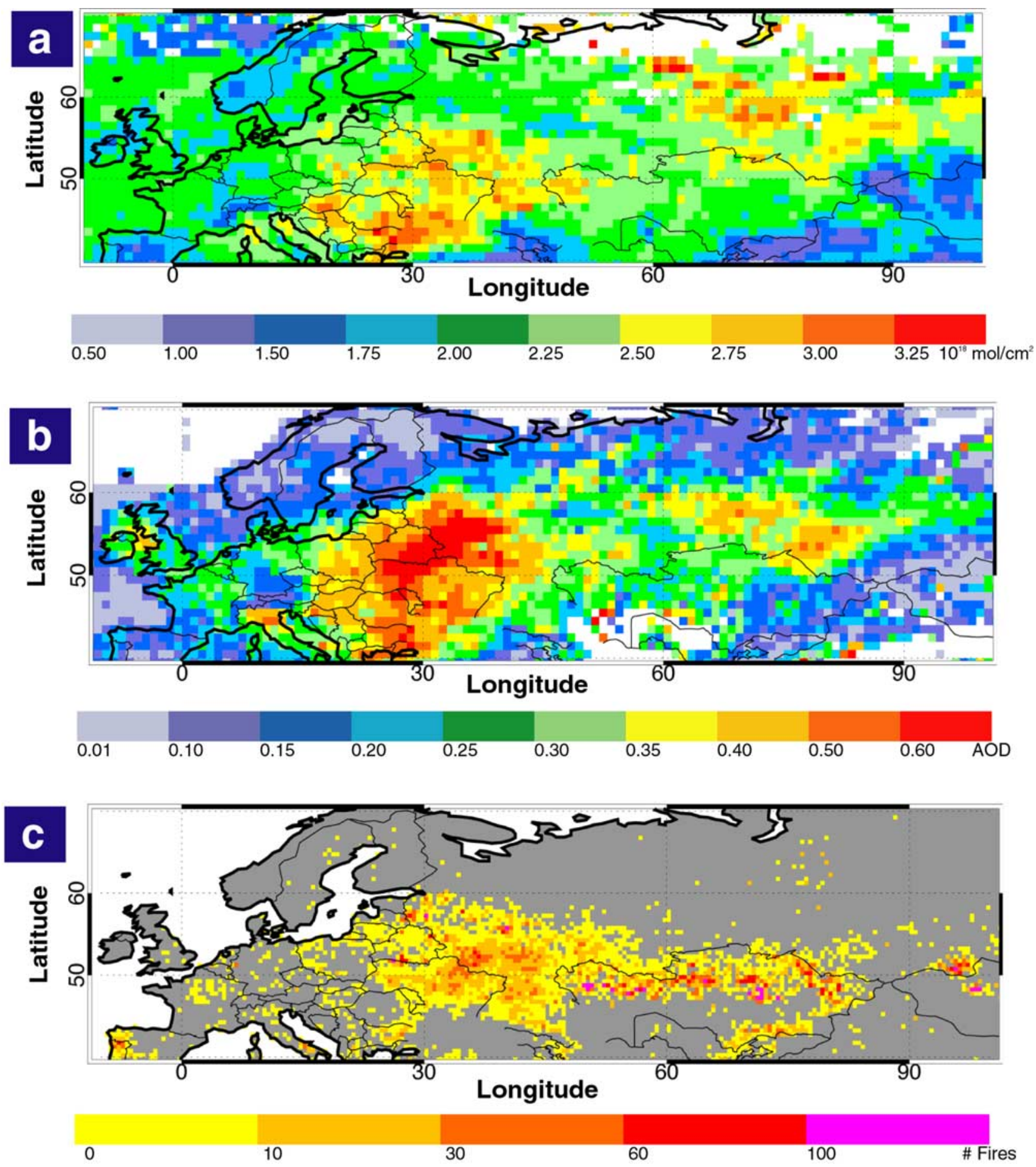

Figure 6. Mean distributions of (a) Terra/MOPITT CO total column, (b) Terra/MODIS fine mode AOD, for 1-15 September 2002, and (c) Terra/MODIS fire counts for August 2002.

are also shown in the figure. This indicates higher winter $\mathrm{CO}$ values as expected from the $\mathrm{NH}$ seasonal cycle of the $\mathrm{OH}$ sink, and does not show high summer loadings. This suggests that the fires of 2002 had an anomalous affect on the local air quality. The peatlands in western Russia were drained some 2 centuries ago and used for agriculture. In recent years, they have received inadequate management because of the poor economic situation [IFFN, 2003].
During summer, western Russia experiences periods of prolonged hot, dry weather which dry the upper layers of the drained peat soils. Fires often start outside of the peatlands, either unintentionally or as a result of agricultural activities, and later spread [IFFN, 2003]. Peat fire emissions of $\mathrm{CO}$ and particulates, mainly in the form of $\mathrm{OC}$, are about twice as high as emissions from forest burning [Levine, 1999]. Figure 7 also shows the daily average of MOPITT 


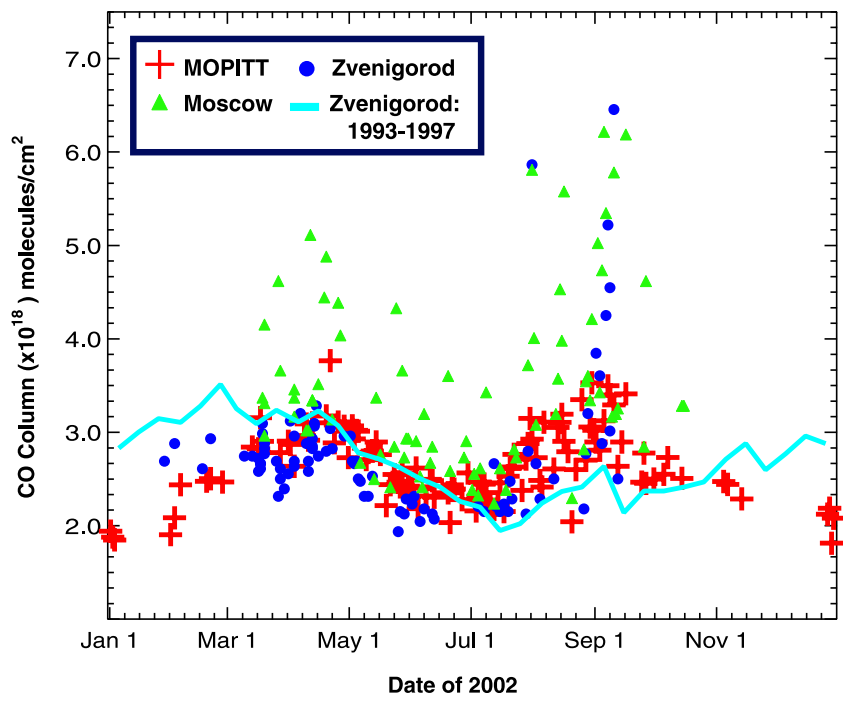

Figure 7. Ground-based infrared grating spectrometer measurements of $\mathrm{CO}$ column from Zvenigorod $\left(55.71^{\circ} \mathrm{N}\right.$, $\left.36.59^{\circ} \mathrm{E}\right)$ and Moscow $\left(55.75^{\circ} \mathrm{N}, 37.70^{\circ} \mathrm{E}\right)$ during 2002. Also shown are the Zvenigorod CO column averaged over the years 1993-1997 and the daily MOPITT measurements during 2002 averaged over a $200 \mathrm{~km}$ radius of Zvenigorod.

$\mathrm{CO}$ total column measurements within a $200 \mathrm{~km}$ radius of Zvenigorod. In general, the agreement is very good between the spectrometer and MOPITT data considering the very different measurement sensitivities. In contrast to the MOPITT measurements, the spectrometer data are sensitive to the boundary layer. They also represent local conditions, whereas a larger area must be considered to obtain sufficient MOPITT data for comparison purposes (see Emmons et al. [2004] for a discussion of MOPITT data comparison criteria with localized measurements). As a result, the spectrometer measurements are able to capture the very high $\mathrm{CO}$ column values, greater than $6 \times 10^{18}$ molecules $/ \mathrm{cm}^{2}$, which probably represent the very polluted condition of the local boundary layer in the vicinity of the peat fires. Although such high values are not seen at MOPITT resolution, a pronounced increase in the $\mathrm{CO}$ column is also observed at this time.

[28] For these fire events, the correlation between the CO column and fine mode AOD was also high. This is shown in Figure 8, where the MODIS fine mode AOD and MOPITT CO column daily $1^{\circ}$ horizontal mean values are compared as scatterplots for all measurements during the periods $1-10$ September of 2000 and 2002 . This has been done for a new region $\left(35^{\circ}-65^{\circ} \mathrm{N}, 0^{\circ}-60^{\circ} \mathrm{E}\right)$ that includes part of industrialized Europe in addition to part of western Russia. In 2000, the correlation between the measurements was poor, whereas it was very good in 2002 with a coefficient of 0.74 . In the former case, the principal aerosol contributing to the regional fine mode AOD was most likely sulfate arising from industrial $\mathrm{SO}_{2}$ emissions. In 2002, the aerosols would be a combination of industrial sulfate and primary carbonaceous particles from the fires. Good correlation between the pollutants is only to be expected when direct emissions of both $\mathrm{CO}$ and aerosol from a common source dominate the local fields, as is the case with the fires in 2002. Correlation of $\mathrm{CO}$ and sulfate over industrial sources is much weaker because of the fact that the $\mathrm{SO}_{2}$ requires chemical processing before sulfate aerosol is formed. Transport also likely plays a role since a component of the measured $\mathrm{CO}$, because of its longer lifetime, might have originated very far away. Consideration of the correlation between AOD and CO column in similar scatterplots for other regions (not shown) support these conclusions. Good correlation is obtained over wildfire and biomassburning regions, while the correlation is generally poor over purely industrial regions. This suggests that a high degree of correlation between the fine mode AOD and $\mathrm{CO}$ is indicative of carbonaceous particles composing a significant fraction of the fine mode.

[29] Our analysis of fire count data over Russia shows that fires are common events throughout the summer months. These make a significant contribution to the variability of fine mode AOD zonal mean, Figure 3, each summer at latitudes around $50^{\circ} \mathrm{N}$. Given the relatively short aerosol lifetime, these fires have only a short-term, local to regional, effect on the AOD loading, even though the perturbation may be considerable. As noted above, Russian fires decease from August and are absent during the winter months. The effect of late summer fires on the wintertime CO levels is important however. During the summer months, the $\mathrm{CO}$ from the fires is relatively shorter lived because of the high atmospheric $\mathrm{OH}$ concentrations. The latter begin to decrease after July and August [Spivakovsky et al., 2000], and if this coincides with strong fires, the resultant $\mathrm{CO}$ has a significant impact on the zonal loading for several months.

[30] We have performed a study using Model of Ozone and Related Tracers 2 (MOZART-2) [Horowitz et al., 2003] to investigate this further. A "tagged" pulse of CO [Granier et al., 1999] was released in the model from an area in western Russia $\left(52^{\circ}-57^{\circ} \mathrm{N}, 30^{\circ}-35^{\circ} \mathrm{E}\right)$ close to the fires of September 2002, with the aim of quantifying how long the $\mathrm{CO}$ persisted. The same pulse was released during 4 separate months, July to October, with the emission being constant during the test month. The resulting $\mathrm{CO}$ total atmospheric loading as a function of time for each case is shown in Figure 9. This shows the buildup of $\mathrm{CO}$ in the model during the emission month and the subsequent decay of the loading according to the seasonally changing $\mathrm{OH}$ sink. The concentrations of $\mathrm{OH}$ are close to their peak values in July, and the buildup of $\mathrm{CO}$ for a given total emission is only half that produced for a pulse during October. In addition to this, the duration of the CO loading depends critically on the emission month. The $e$-folding CO lifetime varies from about 1.5 months for the July pulse, to about 3.6 months for the October pulse. Given the high resultant burden and long relative lifetime of $\mathrm{CO}$ emitted from the late season fires, it is evident that these will have a significant effect on the zonal loading throughout the winter months. We conclude that the eastern European and western Russian fires of August and September 2002 were thus well timed to bring about the early start to the winter 2002-2003 $\mathrm{CO}$ maximum in the $\mathrm{NH}$.

[31] We turn now to consideration of the 2003 Russian fires of the following spring and summer. Spring fires in eastern Russia occur first in the southern areas bordering China and Mongolia, and then move northward through Siberia during the summer. They start with snowmelt and 

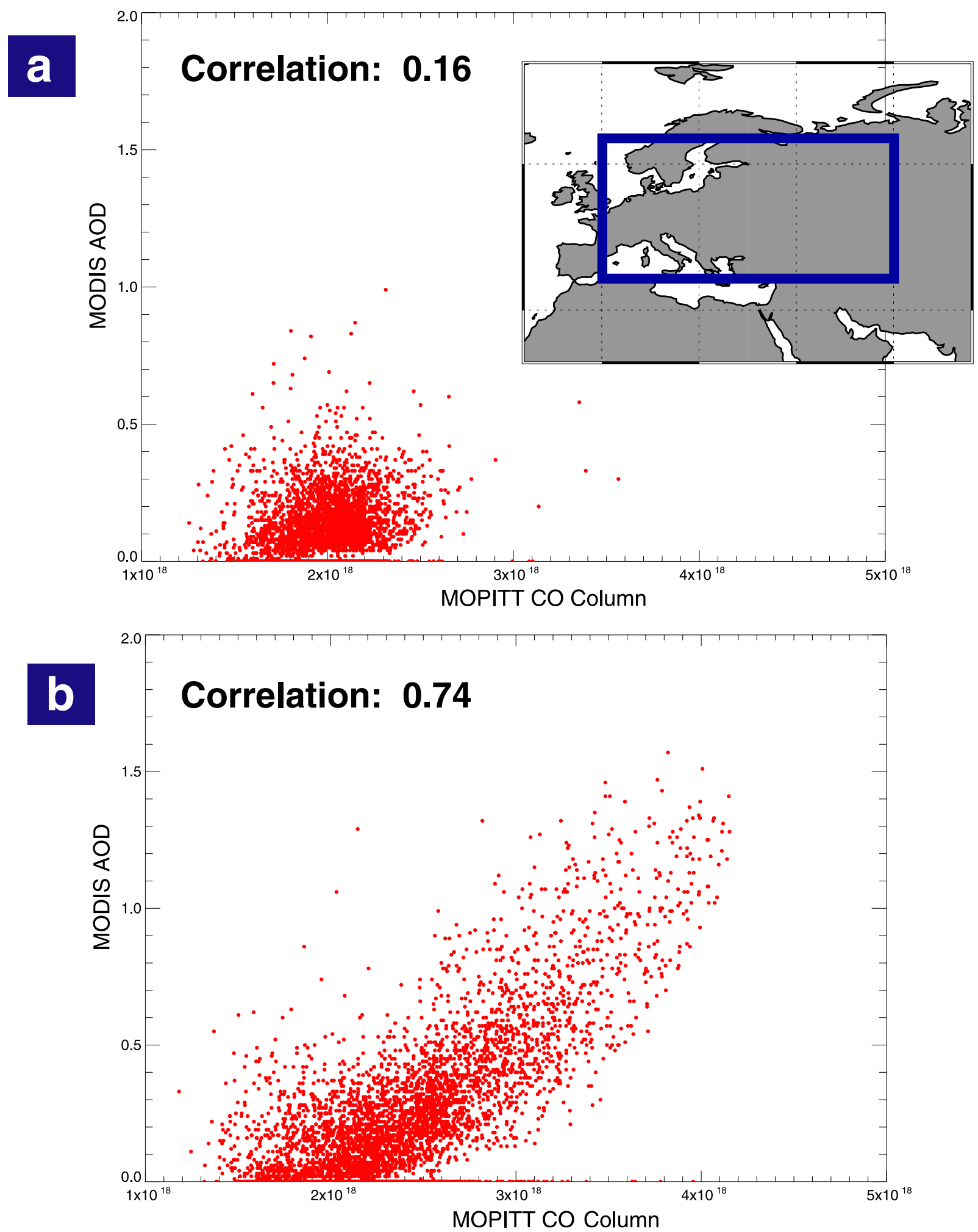

Figure 8. Scatterplot of MODIS fine mode AOD and MOPITT CO total column over eastern Europe/ western Russia $\left(35^{\circ}-65^{\circ} \mathrm{N}, 0^{\circ}-60^{\circ} \mathrm{E}\right)$, for $1-10$ September for the years (a) 2000 and (b) 2002.

rapid drying of forest fuel at the onset of dry weather in March and April [IFFN, 2003]. The most intense fires burned in the Baikal region. The average distributions of CO, AOD and MODIS fire counts over Russia, the Pacific Ocean and North America in May 2003 are shown in
Figure 10. Good correlation is seen between the fire regions and areas of high aerosol and CO loading. There is also clear indication that the plumes generated by these fires were transported eastward, over northern China, and continued out into the Pacific Ocean. These plumes are also 


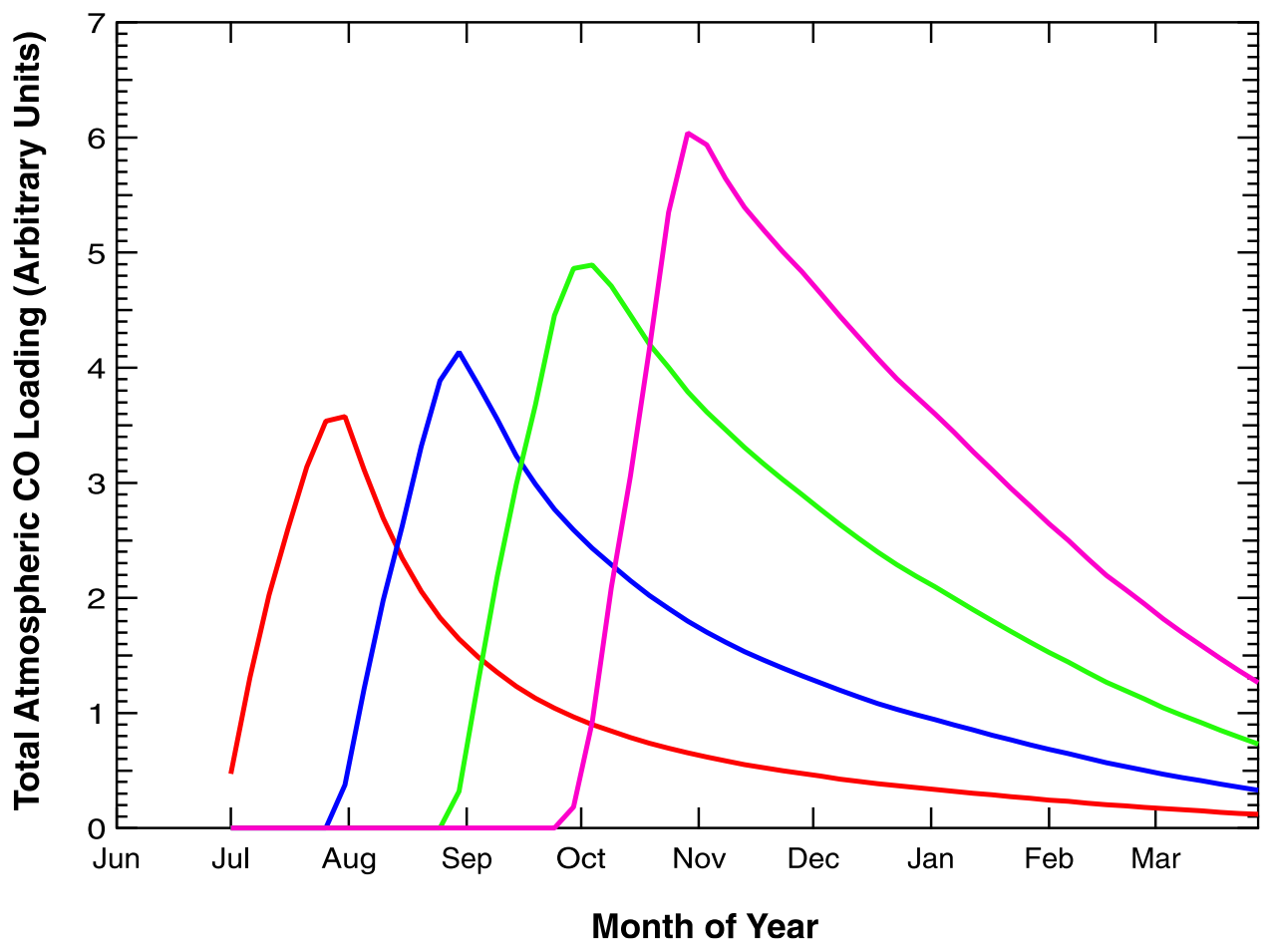

Figure 9. MOZART-2 calculations of the total atmospheric CO loadings resulting from the same constant monthlong emission pulse set off in either July, August, September, or October. In each case, the emissions were evenly distributed over a region in western Russia $\left(52^{\circ}-57^{\circ} \mathrm{N}, 30^{\circ}-35^{\circ} \mathrm{E}\right)$.

enhanced by the residual contribution of emissions from the yearly biomass burning that takes pace further south in southeast Asia from February to April. In the case of CO, the plume can be traced to North America. The MOPITT $\mathrm{CO}$ data often show plumes from Asia following the Jet Stream, and high levels of $\mathrm{CO}$ are seen stretching from western Canada, down through the Midwest to the east coast of the United States. Wildfires in British Columbia, Canada, also contributed. This transport pattern resulted in the high CO columns observed over the eastern United States at this time as discussed in the previous section. The summer fire season produced large numbers of fires in far eastern Russia and Siberia during July and August 2003. The Russian Emergencies Ministry was quoted in news reports as saying that this may have been the worst year on record for forest fires in the region (http://english.pravda.ru/ society/2001/07/24/10858.html). The impact of such intense emissions on the zonal pollutant loadings is significant, and as consideration of Figures 2 and 3 shows, both the zonal fine mode AOD and CO loadings were particularly high compared to the previous years.

\section{Conclusions}

[32] The combination of measurements from the new tropospheric satellite sensors will play an increasingly important role in explaining chemistry and transport processes in the lower atmosphere. Recent developments in aerosol retrieval techniques allow a distinction between fine and coarse mode particles. The fine mode particles are produced predominantly by anthropogenic combustion processes, which also lead to the emission of $\mathrm{CO}$ into the atmosphere. In this paper, we have presented the first comparison of the Terra/MODIS fine mode AOD and Terra/MOPITT CO column global distributions, seasonal cycles, and recent interannual variability. Although not a direct measure of atmospheric burden, the AOD is related to the aerosol column and serves as a good indicator of aerosol loading. This work is important for quantifying the effect of local emissions on the larger-scale pollution distribution, and also for providing a regional or global context to measurements taken at a specific time and location.

[33] The main conclusions of this study are detailed below.

[34] 1. In general, both the CO column and AOD show highest concentrations in the $\mathrm{NH}$. This reflects the greater population and the fact that the primary sources are anthropogenic. In urban regions, sulfate aerosol is the dominant contributor to the NH fine mode AOD zonal mean. In the $\mathrm{SH}$, large emission events such as biomass burning are the dominant sources and punctuate the seasonal cycle each year. Carbonaceous particles form the principal fine mode aerosol type in smoke from fires. The shifting latitudinal pattern of dry season burning dominates the observed pollutant distributions

[35] 2. When considering the usual $\mathrm{NH}$ zonal values, both the $\mathrm{CO}$ and AOD seasonal cycles are driven primarily by the atmospheric oxidant loading, which is greatest during the summer months. This determines the primary sink of $\mathrm{CO}$ and the production of sulfate aerosol. As a consequence, the seasonal cycles are several months out of phase. CO loading usually peaks in April and reaches a minimum in September. AOD shows a broad summer maximum from April to August and a minimum in December. Perturbations 

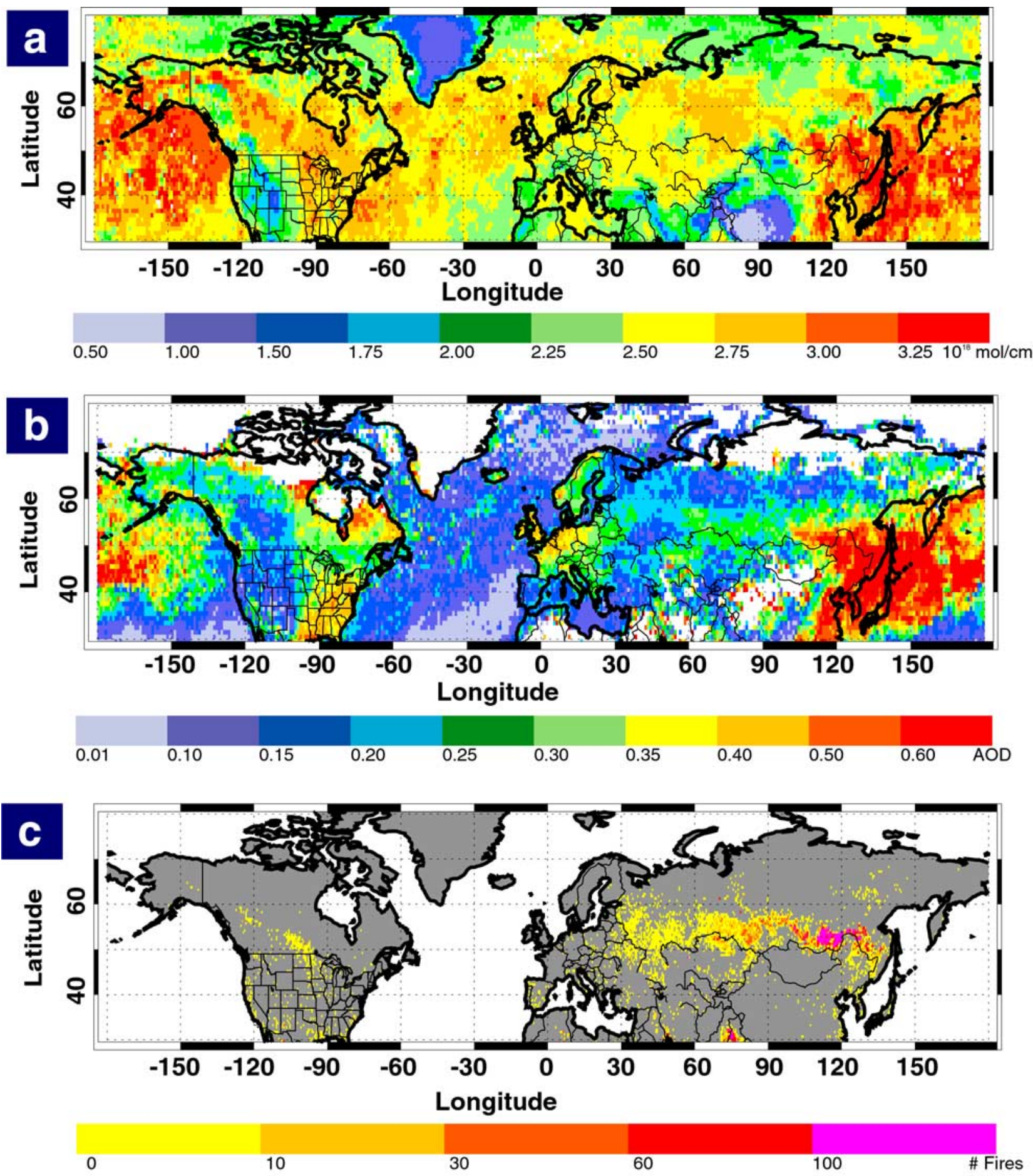

Figure 10. May 2003 mean distributions of (a) Terra/MOPITT CO total column, (b) Terra/MODIS fine mode AOD, and (c) Terra/MODIS fire counts.

in these cycles are usually a direct result of sporadic wildfire or biomass-burning emissions.

[36] 3. Wildfires and biomass burning generally provide the best correlation between CO column and AOD. This is because direct emissions of both $\mathrm{CO}$ and aerosol from a common source dominate the measurements. Correlation of $\mathrm{CO}$ and sulfate over industrial sources is weaker because of the fact that the $\mathrm{SO}_{2}$ must be chemically processed to form sulfate, and because of transport of the longer-lived CO into the measurement area from other regions. Put another way, a high degree of correlation between the fine mode AOD and $\mathrm{CO}$ is indicative of carbonaceous particles composing a significant fraction of the fine mode aerosol.

[37] 4. The MODIS AOD measurement is more sensitive to the boundary layer than the MOPITT CO measurement. This, combined with the fact that the average $\mathrm{CO}$ lifetime, at a couple of months, is much longer than the several day lifetime of the predominant $\mathrm{OC}$ aerosol emitted by fires 
means that high AOD retrievals are a more reliable indication of wildfire and biomass-burning locations than the $\mathrm{CO}$, which tends to 'smear out' the signature. Conversely, the MOPITT CO measurement is more useful for tracing longrange transport of fire emissions. The two measurements are therefore complementary in building up the overall picture of plume evolution.

[38] 5. Of the 4 years of data available from the Terra satellite, the winter and spring of 2002-2003 showed anomalously high $\mathrm{NH}$ pollutant loadings compared to the previous years. Eastern European and western Russian peat and forest fires in the late summer and fall of 2002 resulted in high emissions of both $\mathrm{CO}$ and carbonaceous aerosol. This produced an early buildup of the $\mathrm{NH}$ winter $\mathrm{CO}$, and concentrations reached a minimum in July 2002, two months earlier than the previous year. Our model sensitivity studies indicate that such high emissions, late in the year when the $\mathrm{OH}$ concentrations are falling, can produce a particularly high CO loading all through the winter months. The high pollutant levels of both $\mathrm{CO}$ and AOD measured in the spring of 2003 were again much higher than the previous years and resulted from agricultural and wildfire emissions from southeastern Russia. These produced high AOD out over the Pacific Ocean and significantly affected the CO loading as far away as the eastern United States.

[39] It is clear that boreal fires can have a significant impact on NH pollutant loadings. It is also clear that there are large changes, year-to-year, in these emissions. This is in contrast to the relatively constant industrial emissions of $\mathrm{CO}$ and $\mathrm{SO}_{2}$. Despite the large impact on $\mathrm{NH}$ air quality shown here and by others [Crutzen et al., 1998; Wotawa and Trainer, 2000; Forster et al., 2001], there is considerable uncertainty in the fire emission inventories for the boreal forest regions of Russia and Canada [Wotawa et al., 2001; $I F F N, 2003]$. Studies in northern Canada show that the burnt area has almost doubled in the 1980s compared to the period 1930-1960 [Weber and Stocks, 1998], and that this is consistent with modeling studies that suggest an increase in the number of fires with higher temperatures [Stocks et al., 1998]. In Russia, fire statistics are known to be systematically too low [Conard and Ivanova, 1998], and the statistical study of Wotawa et al. [2001] using CO data from CMDL in situ sites for the period 1991-1999, suggests that the number of fires is underreported by a factor of about 3 . They find that the $\mathrm{CO}$ source term from the statistically corrected burnt area in Russia and North America approaches the anthropogenic emissions of the United States and Europe. Given the difficulties in obtaining a "bottom-up" estimate of the emissions from Russian fires, there is clearly a role for satellite data. This was done previously in the case of the western U.S. wildfires of 2000 by Lamarque et al. [2003], who used satellite-derived estimates of burnt area in conjunction with MOPITT CO data and the MOZART-2 CTM to estimate the total fire CO emissions.

[40] The observations presented here point to the utility of the satellite measurements in providing global distributions of the emission fields within a few days, indications of fires as they occur, and characterization of the impact of these fires on both the seasonal variations and interannual variability. With the current 4-year record from the Terra satellite it is too soon to look for significant trends in $\mathrm{CO}$ and aerosol loading, as opposed to short-term variations which may or may not be part of a trend. Within a few years, the growing satellite data set should contribute significantly to this debate. The work described in this paper provides an investigation of the available satellite data and a basis for future modeling studies. The MOPITT $\mathrm{CO}$ and MODIS AOD products could be combined in an inverse modeling scheme to mutually improve emission estimates of each. The better MODIS characterization of source regions applicable to both fine mode aerosol and CO, should help deconvolve the transport uncertainties from the estimation of $\mathrm{CO}$ emissions. Correlations between $\mathrm{CO}$ and AOD would also help distinguish carbonaceous and sulfate fine mode particles. With the aid of these measurements, the improved model characterization of the $\mathrm{CO}$ and aerosol fields should pave the way for better estimates of the effect of anthropogenic emissions on photolysis, heterogeneous chemistry, and the regional budget of key tropospheric oxidants.

[41] Acknowledgments. The MOPITT team at the University of Toronto, Toronto, Ontario, Canada, are acknowledged for their continued support of MOPITT instrument operations. We would like to thank P. Rasch, P. Hess, and X. Tie at NCAR for very useful discussions. We also thank A. V. Dzhola and E. V. Fokeeva, Institute of Atmospheric Physics, Moscow, Russia, for providing us with $\mathrm{CO}$ spectrometer measurements that were supported by Russian Fund for Basic Research grant RFBR 02-05-64148. We acknowledge the work of the NOAA CMDL group in making in situ measurements and maintaining the Interactive Atmospheric Data Visualization web tools, which were useful in providing "ground truth" to the satellite measurements time series. The NCAR work was partly supported by NASA grant NNG04GA45G. The National Center for Atmospheric Research is sponsored by the National Science Foundation.

\section{References}

Adriano, D. C., and A. H. Johnson (1989), Acidic Precipitation, vol. 2 Biological and Ecological Effects, Springer-Verlag, New York.

Andreae, M. O. (1991), Biomass burning: Its history, use, and distribution, and its impact on environmental quality and global climate, in Global Biomass Burning, edited by J. S. Levine, pp. 3-21, MIT Press, Cambridge, Mass.

Andreae, M. O., and P. Merlet (2001), Emission of trace gases and aerosols from biomass burning, Global Biogeochem. Cycles, 15, 955-966.

Barth, M. C., P. J. Rasch, J. T. Kiehl, C. M. Benkovitz, and S. E. Schartz (2000), Sulfur chemistry in the National Center for Atmospheric Research Community Climate Model: Description, evaluation, features, and sensitivity to aqueous chemistry, J. Geophys. Res., 105, 13871415.

Beeson, W. L., D. E. Abbey, and S. F. Knutson (1998), Long-term concentrations of ambient air pollutants and incident lung cancer in California adults: Results from the AHSMOG Study, Environ. Health Perspect., 106, 813-822.

Benkovitz, C. M., M. T. Sholtz, J. Pacyna, L. Tarrason, J. Dignon, E. C. Voldner, P. A. Spiro, J. A. Logan, and T. E. Graedel (1996), Global gridded inventories of anthropogenic emissions of sulfur and nitrogen, J. Geophys. Res., 101, 29,239-29,254.

Bian, H., M. J. Prather, and T. Takemura (2003), Tropospheric aerosol impacts on trace gas budgets through photolysis, J. Geophys. Res., 108(D8), 4242, doi:10.1029/2002JD002743.

Cautenet, S., D. Poulet, C. Delon, R. Delmas, J.-M. Grégoire, J. M. Pereira, S. Cherchali, O. Amram, and G. Flouzat (1999), Simulation of carbon monoxide redistribution over central Africa during biomass burning events (Experiment for Regional Sources and Sinks of Oxidants (EXPRESSO)), J. Geophys. Res., 104, 30,641-30,657.

Chameides, W. L., et al. (1999), Case study of the effects of atmospheric aerosols and regional haze on agriculture: An opportunity to enhance crop yields in China through emission control, Proc. Natl. Acad. Sci. U. S. A., 96, 13,626-13,633.

Chin, M., P. Ginoux, S. Kinne, O. Torres, B. N. Holben, B. N. Duncan, R. V. Martin, J. A. Logan, A. Higurashi, and T. Nakajima (2002), Tropospheric serosol optical thickness from the GOCART model and comparisons with satellite and Sun photometer measurements, J. Atmos. Sci., 59, 461-483. 
Chu, D. A., Y. J. Kaufman, C. Ichoku, L. A. Remer, D. Tanré, and B. N. Holben (2002), Validation of MODIS aerosol optical depth retrieval over land, Geophys. Res. Lett., 29(12), 8007, doi:10.1029/2001GL013205.

Chu, D. A., Y. J. Kaufman, G. Zobordi, J. D. Chern, J. Mao, C. Li, and B. N. Holben (2003), Global monitoring of air pollution over land from the Earth Observing System-Terra Moderate Resolution Imaging Spectroradiometer (MODIS), J. Geophys. Res., 108(D21), 4661, doi:10.1029/ 2002JD003179.

Cicerone, R. J. (1988), How has the atmospheric concentration of CO changed?, in The Changing Atmosphere, edited by F. S. Rowland and I. S. A. Isaksen, pp. 49-61, John Wiley, Hoboken, N. J.

Conard, S. G., and G. A. Ivanova (1998), Wildfire in Russian boreal forests: Potential impacts of the fire regime characteristics on emissions and global carbon balance estimates, Environ. Pollut., 98, 305-313

Crutzen, P. J., et al. (1998), Trace gas measurements between Moscow and Vladivostok using the Trans-Siberian Railroad, J. Atmos. Chem., 29, $179-194$

Deeter, M. N., et al. (2003), Operational carbon monoxide retrieval algorithm and selected results for the MOPITT instrument, J. Geophys. Res., 108(D14), 4399, doi:10.1029/2002JD003186.

Deeter, M. N., et al. (2004), Evaluation of operational radiances for the Measurements of Pollution in the Troposphere (MOPITT) instrument CO thermal band channels, J. Geophys. Res., 109, D03308, doi:10.1029/ 2003JD003970.

Dianov-Klokov, V. I., L. N. Yurganov, E. I. Grechko, and A. V. Dzhola (1989), Spectroscopic measurements of atmospheric carbon monoxide and methane. 1: Latitudinal distribution, J. Atmos. Chem., 8, 139-151.

Drummond, J. R. (1992), Measurements of Pollution in the Troposphere (MOPITT), in The Use of EOS for Studies of Atmospheric Physics, edited by J. C. Gille and G. Visconti, pp. 77-101, North-Holland, New York.

Edwards, D. P., C. Halvorson, and J. C. Gille (1999), Radiative transfer modeling for the EOS Terra satellite Measurement of Pollution in the Troposphere (MOPITT) instrument, J. Geophys. Res., 104, 16,75516,775 .

Edwards, D. P., et al. (2003), Tropospheric ozone over the tropical Atlantic: A satellite perspective, J. Geophys. Res., 108(D8), 4237, doi:10.1029/ 2002JD002927.

Emmons, L. K., et al. (2004), Validation of Measurements of Pollution in the Troposphere (MOPITT) CO retrievals with aircraft in situ profiles, J. Geophys. Res., 109, D03309, doi:10.1029/2003JD004101.

Ferek, R. J., J. S. Reid, P. V. Hobbs, D. R. Blake, and C. Liousse (1998) Emission factors of hydrocarbons, halocarbons, trace gases and particles from biomass burning in Brazil, J. Geophys. Res., 103, 32,107-32,118.

Fokeeva, E. V., E. I. Grechko, A. V. Dzhola, and A. A. Boriskin (2004), Spectroscopic measurements of the total column contents of $\mathrm{CO}$ in the atmosphere over Moscow and Zvenigorod Scientific Station (in Russian), in The Annals of Weather, Climate and Ecology of Moscow in 2002, edited by A. A. Isaev, Hydrometeoizdat, Saint Petersburg, Russia, in press.

Forster, C., et al. (2001), Transport of boreal forest fire emissions from Canada to Europe, J. Geophys. Res., 106, 22,887-22,906.

Giglio, L., J. Descloitres, C. O. Justice, and Y. J. Kaufman (2003), An enhanced contextual fire detection algorithm for MODIS, Remote Sens. Environ., 87, 273-282.

Granier, C., J.-F. Mueller, G. Pétron, and G. Brasseur (1999), A threedimensional study of the global CO budget, Chemosphere, 1, 255-261.

Herman, J. R., P. K. Bhartia, O. Torres, C. Hsu, C. Seftor, and E. Celaeier (1997), Gobal distribution of UV-absorbing aerosols from Nimbus 7/TOMS data, J. Geophys. Res., 102, 16,911-16,922.

Horowitz, L. W., et al. (2003), A global simulation of tropospheric ozone and related tracers: Description and evaluation of MOZART, version 2, J. Geophys. Res., 108(D24), 4784, doi:10.1029/2002JD002853.

Intergovernmental Panel on Climate Change (2001), Climate Change 2001: The Scientific Basis, Contribution of Working Group I to the Third Assessment Report of the Intergovernmental Panel on Climate Change, edited by J. T. Houghton et al., 881 pp., Cambridge Univ. Press, New York.

International Forest Fire News (IFFN) (2003), Russian Federation 2002 Fire Special, Int. Forest Fire News, 28, Parts I-IV, 2-32.

Jacobson, M. Z. (2001), Strong radiative heating due to the mixing state of black carbon in atmospheric aerosols, Nature, 409, 695-697.

Kanakidou, M., and P. J. Crutzen (1999), The photochemical source of carbon monoxide: Importance, uncertainties and feedbacks, Chemosphere, 1, 91-109.

Kaufman, Y. J., D. Tanré, L. Remer, E. Vermote, A. Chu, and B. N. Holben (1997), Remote sensing of tropospheric aerosol from EOS-MODIS over the land using dark targets and dynamic aerosol models, J. Geophys. Res., $102,17,051-17,067$

Kaufman, Y. J., D. Tanré, and O. Boucher (2002a), A satellite view of aerosols in the climate system, Nature, 419, 215-223.
Kaufman, Y. J., N. Gobron, B. Pinty, J.-L. Widlowski, and M. M. Verstraete (2002b), Relationship between surface reflectance in the visible and the mid-IR used in MODIS aerosol algorithm: Theory, Geophys. Res. Lett., 29(23), 2116, doi:10.1029/2001GL014492.

Lamarque, J.-F., et al. (2003), Identification of CO plumes from MOPITT data: Application to the August 2000 Idaho-Montana forest fires, Geophys. Res. Lett., 30(13), 1688, doi:10.1029/2003GL017503.

Levine, J. S. (1999), The 1997 fires in Kalimantan and Sumatra, Indonesia: Gaseous and particulate emissions, Geophys. Res. Lett., 26, 815-818.

Liousse, C., J. E. Penner, C. Chang, J. J. Walton, H. Eddleman, and H. Cachier (1996), A global three-dimensional model study of carbonaceous aerosols, J. Geophys. Res., 101, 19,411-19,432.

Logan, J. A., M. J. Prather, S. C. Wofsy, and M. B. McElroy (1981), Tropospheric chemistry: A global perspective, J. Geophys. Res., 86, 7210-7254. Martin, R. V., D. J. Jacob, R. M. Yantosca, M. Chin, and P. Ginoux (2003), Global and regional decreases in tropospheric oxidants from photochemical effects of aerosols, J. Geophys. Res., 108(D3), 4097, doi:10.1029/ 2002JD002622.

Nielsen, T. T. (1999), Characterization of fire regimes in the Experiment for Regional Sources and Sinks of Oxidants (EXPRESSO) study area, J. Geophys. Res., 104, 30,713-30,723.

Novelli, P. C., K. A. Masarie, and P. M. Lang (1998), Distributions and recent changes in carbon monoxide in the lower troposphere, J. Geophys. Res., 103, 19,015-19,033.

Olivier, J. G. J., A. F. Bouwmann, C. W. M. Van der Maas, J. J. M. Berdowski, C. Veldt, J. P. J. Bloos, A. J. H. Visschedijk, P. Y. J. Zandveld, and J. L. Haverlag (1996), Description of EDGAR Version 2.0: A set of global emission inventories of greenhouse gases and ozone-depleting substances for all anthropogenic and most natural sources on a per country basis and on $1 \times 1$ grid, RIVM Rep. 771060 002, TNO-MEP Rep. R96 119, Natl. Inst. of Public Health and the Environ., Bilthoven, Netherlands.

Rasch, P. J., M. C. Barth, J. T. Kiehl, S. E. Schwartz, and C. M. Benkovitz (2000), A description of the global sulfur cycle and its controlling processes in the National Center for Atmospheric Research Community Climate Model, Version 3, J. Geophys. Res., 105, 1367-1385.

Remer, L. A., et al. (2002), Validation of MODIS aerosol retrieval over ocean, Geophys. Res. Lett., 29(12), 8008, doi:10.1029/2001GL013204.

Ridley, B. A., S. Madronich, R. B. Chatfield, J. G. Walega, R. E. Shetter, M. A. Carroll, and D. D. Montzka (1992), Measurements and model simulations of the photostationary state during the Mauna Loa Observatory Photochemistry Experiment: Ozone production and loss rates, J. Geophys. Res., 97, 10,375-10,388.

Rodgers, C. D. (2000), Inverse Methods for Atmospheric Sounding, World Sci., River Edge, N. J.

Rosenfeld, D. (1999), TRMM observed first direct evidence of smoke from forest fires inhibiting rainfall, Geophys. Res. Lett., 26, 3105-3108.

Rosenfeld, D. (2000), Suppression of rain and snow by urban and industrial air pollution, Science, 287, 1793-1796.

Spivakovsky, C. M., et al. (2000), Three-dimensional climatological distribution of tropospheric OH: Update and evaluation, J. Geophys. Res., $105,8931-8980$

Stocks, B. J., et al. (1998), Climate change and forest fire potential in Russian and Canadian boreal forests, Clim. Change, 38, 1-13.

Tager, I. B. (1993), Introduction to working group on tropospheric ozone, Health Effects Institute Environmental Epidemiology Planning Project, Environ. Health Perspect., 101, 205-207.

Tanré, D., Y. J. Kaufman, M. Herman, and S. Mattoo (1997), Remote sensing of aerosol over oceans from EOS-MODIS, J. Geophys. Res., $102,16,971-16,988$.

Thompson, A. M. (1992), The oxidizing capacity of the Earth's atmosphere: Probable past and future changes, Science, 256, 1157-1165.

Ward, D. E., W. M. Hao, R. A. Susott, R. E. Babbitt, R. W. Shea, J. B. Kauffman, and C. O. Justice (1996), Effect of fuel composition on combustion efficiency and emission factors for African savanna ecosystems, J. Geophys. Res., 101, 23,569-23,576.

Weber, M. G., and B. J. Stocks (1998), Forest fires and sustainability in the boreal forests of Canada, Ambio, 27, 545-550.

Wotawa, G., and M. Trainer (2000), The influence of Canadian forest fires on pollutant concentrations in the United States, Science, 288, 324-328.

Wotawa, G., P. C. Novelli, M. Trainer, and C. Granier (2001), Inter-annual variability of summertime $\mathrm{CO}$ concentrations in the Northern Hemisphere explained by boreal forest fires in North America and Russia, Geophys. Res. Lett., 28, 4575-4578.

J. Chen, M. N. Deeter, D. P. Edwards, L. K. Emmons, G. L. Francis, J. C. Gille, S. P. Ho, J.-F. Lamarque, D. Mao, G. Pétron, J. Warner, V. Yudin, and D. C. Ziskin, National Center for Atmospheric Research, P. O. Box 3000, Boulder, CO 80307-3000, USA. (jschen@ucar.edu; mnd@ucar.edu; edwards@ucar.edu; emmons@ucar.edu; gfrancis@ucar.edu; gille@ucar. 
edu; spho@ucar.edu; lamar@ucar.edu; dmao@ucar.edu; gap@ucar.edu; juying@ucar.edu; vyudin@ucar.edu; ziskin@ucar.edu)

D. A. Chu, Joint Center for Earth Systems Technology, University of Maryland, Baltimore County, 1000 Hilltop Circle, Baltimore, MD 21250, USA. (achu@climate.gsfc.nasa.gov)

J. R. Drummond, Department of Physics, University of Toronto, St. George Street, Toronto, ON, Canada M5S 1AS. (james.drummond@utoronto.ca)

E. I. Grechko, Obukhov Institute of Atmospheric Physics, Pyzhevsky 3, 109017 Moscow, Russia. (grechko@ifaran.ru)
L. Giglio and Y. J. Kaufman, NASA Goddard Space Flight Center, Greenbelt, MD 20771, USA. (giglio@hades.gsfc.nasa.gov; kaufman@ climate.gsfc.nasa.gov)

D. A. Hauglustaine, Laboratoire des Sciences du Climat et de l'Environnement, Bât. 709, Orme des Merisiers, F-91191 Gif-sur-Yvette Cedex, France. (hauglustaine@cea.fr)

L. N. Yurganov, Frontier Research System for Global Change, 3173-25 Showa-machi, Kanazawa-ku, Yokohama, 236-0001 Japan. (leonid@) jamstec.go.jp) 